\title{
MENTAL HEALTH POLICY: OPTIONS FOR SOUTH AFRICA
}

\author{
Y.G. Pillay
}

\section{INTRODUCTION}

There is a dearth of cited literature on South African mental health policy. This was reflected in a review of the PsycLit data base for the period January 1983 to December 1991. The following reasons are speculated as being contributory to this 'silence': (a) the development of policy has traditionally been considered to be the function of the state and state appointed consultative bodies; (b) a direct consequence of the lack of popular participation by people in public policy decision making at all levels, fostered by the restriction of democracy to the white population; (c) the lack of interest, by mental health professionals, in debating mental health policy; and (d) the lack of expertise and training in this area as a consequence of the lack of emphasis of this area of specialization in academic training institutions. These reasons should not be seen as mutually exclusive but should be considered to be inter-related.

Theories of crises and the potential that they offer for change are well documented in the literature. It can be suggested that South Africa finds itself in the midst of the possibility of political change which should create the potential for changes in public policies of all types (including mental health policy). Mental health professionals should anticipate this possibility and act accordingly in order to maximize the potential for substantial changes to the current mental health system (which has long been criticized by a wide range of mental health workers e.g. Vogelman 1989).

The relatively recent awareness of the need to develop alternative national policies, possibly stimulated by the general climate of debates about constitutional reform, has sparked a renewal of interest in reformulating national health policy. This is reflected in even traditionally conservative journals like the South African Medical Journal which has, especially since the late $1980 \mathrm{~s}$, published numerous articles that have

\begin{abstract}
This paper emphasizes the need for mental health professionals to become involved in developing mental health policies in South Africa. In particular, it examines three options that are currently the focus of attention with respect to national health options, i.e. a free market system, a national health service (NHS) and a national health insurance system (NHIS). While the paperdoes not provide support for any one of these options it does attempt to investigate some of the implications of each option for the funding and delivery of mental health care.
\end{abstract}

articulated the need for a unitary health care service and have documented the extent of the mal-distribution of health care resources in South Africa.

While this level of interest has not been illustrated by the South African mental health professional community in general, there have recently been a few attempts to: (1) provide a conceptual analysis of the tasks facing South African mental health workers (Dawes, 1986; Hayes, 1987; Vogelman, 1989); and (2) respond to the need to restructure the delivery of mental health services (Freeman, 1990 and 1992; The Psychological Association of South Africa; Kriegler, 1989). These two aspects of policy development can be labelled issues of production (imcluding reproduction) and distribution respectively. While many of the references cited above have been written by psychologists, it should be noted that the field of mental health includes a host of professions and practitioners, e.g. psychiatric nurses, psychiatrists, social workers, traditional healers, school counsellors and psychologists.
This paper will attempt to address the need for mental health professionals in South Africa to consider alternative mental health policies and their impact on various constituents e.g. providers, patients or consumers, third party payers or health insurers and the state. An attempt will also be made to situate the discourse of mental health policy within the currently debated national health policy options.

\section{NEED TO CONSIDER HEALTH POLICY OPTIONS}

Mental health practitioners work within a variety of systems. The systems may or may not have been created with input and participation from all who work and live within it. Ideally, systems should be flexible enough to be challenged and changed, if changes are needed to either meet the goals of the system or more fundamentally, to change the goals of the system. It is argued that the current mental health system in South Africa urgently requires evaluation and reform. This perceived need is supported by epidemiological evidence that suggests the extent of the unmet mental health needs (Freeman 1992) of the South African population.

From a narrower perspective, mental health professionals need to be involved in (or at least aware of) mental health policy initiatives because: (1) from a purely careerist perspective, their employment options may depend on their ability to control the supply of, and demand for, mental health care; (2) their collective ability to influence public mental health policy may depend on their ability to identify public mental health issues and draft appropriate policy options that democratically elected public officials may be able to act on; (3) whether or not people consult or keep follow-up appointments may depend on accessibility to the health system (i.e., client or patient outcomes may be policy dependent especially in relation to the barriers to obtaining care); and (4) their practice patterns and reimbursement is 
dependent on mental health policies. This partial list covers a spectrum of reasons including both consumer or patient and mental health provider variables which should be considered in remaking mental health policy.

\section{NATIONAL HEALTH POLICY OPTIONS AND MENTAL HEALTH SERVICES}

Health policies may be differentiated on the basis of whether funding and delivery

freedom of either buying or withholding their purchasing power. This process is the mechanism responsible for regulating the market. Mental health and illnesses therefore are treated like any other product (much like requiring a new stove and searching the market for one that both suits one's needs and financial capacity). Presumably, mental health providers may advertise their 'product' and enter into competition with other 'sellers'. According to the pure form of this model, training and regulation of the

\begin{tabular}{|c|c|c|}
\hline \multicolumn{3}{|c|}{ Typology of heafth policy options } \\
\hline \multirow{2}{*}{ Funding } & \multicolumn{2}{|c|}{ Delivery of Services } \\
\cline { 2 - 3 } & Private & Publlc \\
\hline Private & Market / Family U.S. & NHIS (Canada) \\
\hline Public & & NHS (U.K. / Cuba) \\
\hline
\end{tabular}

of health services are private or public. Table 1 provides a typology of health policy options. It should however be mentioned that these 'pure' types are rarely found in practice. The various options which are currently debated in the South African literature include: (1) one that promotes a system in which the market and the family finance the majority of the health care with the state providing limited and temporary care for those who are unable to finance their own health care requirements and the delivery of services is private (e.g., U.S.A. and to some extent South Africa); (2) a nationalized health care delivery system (NHS), in which the state finances health care from general taxation and in which the providers are state employees (e.g. Cuba, Sweden, and to some extent the U.K. prior to the Thatcher reforms); and (3) the national health insurance service (NHIS), e.g., Canada in which the state funds health care services but the providers of the care are considered to be in the private sector of the economy.

The remainder of the paper will attempt to describe each of these systems and explore some of the implications for mental health services by focusing on the following: impact or benefit, cost and feasibility.

\section{(a) A Predominantly Market Driven System}

This system attempts to follow the free market principles of supply and demand. Under this option mental health practitioners would be treated, by the state, as sellers of a product with purchasers or patients having the mental health providers are accomplished by the demands of the market. In practice, the state can decide either to allow the market to regulate the supply (i.e., those who are not competent will starve out of the profession and the number of mental health workers to be trained be determined entirely by demand) or the state can decide to regulate in a limited way via licensing as is currently the situation.

The operation of the free market assumes that mental health and illness can be equated to any other product and that consumers can delay both purchases (until they have the 'right product at the right price') and have the appropriate knowledge to make informed decisions about the quality of the product and the integrity of the seller. This assumption has been challenged in the literature (Roemer and Roemer, 1982; Pillay, 1992) and this challenge appears to be sustained by practice. There is no country in the world in which the free market is allowed to operate 'freely'. Even in the U.S., which is considered to be the bastion of the free market system, the state and professional organizations mandated by the state intervene in the production and distribution of mental health services. This is accomplished, in part, by the accreditation of university training programmmes, the licensing of mental health workers and the creation of standards of practice.

Using the U.S. as an example of a typical free market system to examine the impact or benefit of the free market alternative, it can be argued that only a minority of the population (maybe the top 5\%, in terms of income) can truly exercise a choice in the purchase of mental health services. The remainder of the population is constrained by either the type of health insurance in terms of what is covered and what excluded or dependence on the public or charity/voluntary health care system.

The impact or benefit to the consumer therefore is at least partly dependent on: (a) who the payer is; (b) what mental health benefits accrue from health insurance; and (c) the type of mental health services available to those dependent on charity and the public health service. Another major issue that determines accessibility to the mental health care system is health-seeking behavior which is influenced by a host of variables ranging from mental health 'problem' detection to what can be called the 'user friendliness' of the system.

In terms of cost, this type of system would place the financial burden on individuals and employers as in the case of a health care system that is dependent on employer-sponsored health insurance as in Germany. The cost to individuals and insurance carriers - and indirectly employers - would be determined by both the criteria used to determine eligibility for benefits and scope of the benefits.

It has been argued, with respect to physical health, that market driven health systems favor the provision of curative services and neglect the provision of preventive care. The same can also be argued for the impact of a market driven system on mental health care. People appear to be more willing to pay for care when they are ill as opposed to paying for care when they are healthy.

Given the current South African political climate, a system such as that described above will not be acceptable to the vast majority of the population because they lack the personal means to finance health care and employer-sponsored health care. The Registrar of Medical Schemes reported that only $6,5 \%$ of the Black population and $20,1 \%$ of the total population was covered by Medical Insurance in 1989. While the report did not provide any indication of the number of people who have mental health coverage it is unlikely to be more substantial than that for general health coverage. Given the relatively small number of the total population having financial capacity and access to employer-sponsored health insurance, it considered unlikely that a predominantly market driven mental health care system will be feasible. 


\section{(b) Nationalized Health Care Service}

In a typical nationalized system all the health care resources e.g., the hospitals and clinics, pharmaceutical and medical appliance companies would be owned by the state. The health workers would be civil servants. Private health care delivery would thus be abolished, creating a single health service with, potentially, one standard of care for all.

Arguably the best known examples of this type of system are the United Kingdom (pre-Thatcher), Sweden, Spain, the former Soviet Union and Cuba.

In the U.K., for example, the fmancing of mental health and other health services is through the National Health Service which is a centralized financing mechanism. However, local health authorities are responsible for the delivery of services. While the same is generally true of social welfare benefits, some social services e.g., home health care for those discharged from hospitals, day centers, half-way houses and rehabilitation programs are both funded and delivered by local authorities (Jansen, 1986).

Spain has a centralized financing mechanism but has been divided into basic health zones, districts, and health areas which are responsible for the delivery of primary, secondary and tertiary mental health care respectively (Poveda et al., 1987).

The impact of the introduction of a National Health Service in South Africa, on mental health providers may be that all those currently in private practice would be absorbed into the national health care system and paid on a salary basis. The catchment area for each practitioner would be determined by both the primary care and curative needs of the population in, for example, a specific geographically or politically defined area. This suggests that the state or local authority would be empowered to determine (on the basis of epidemiological evidence) the number and type of mental health practitioners needed. Mental health worker renumeration could be determined on the basis of negotiated contracts by a union representing them.

Consumers of care whether it be primary, secondary or tertiary/rehabilitative care may be referred to the appropriate mental health care worker by their general practitioner or other primary care provider on the basis on need. This system would remove ability to pay for mental health services as a barrier to access.

Changes in the production or training of mental health workers may result in a transformation of their role and vice versa i.e., from one that is curative and office-based to one that is proactive and community-based and focused on mental illness prevention and mental health promotion.

The cost of this system depends on the number and type - as for example the cost of training a psychiatric nurse is lower than the costs of training a neurologist or psychiatrist - of mental health workers required. While the state currently employs a number of mental health workers in all categories, this number would have to be increased and their job descriptions changed to meet changing needs and newly developed goals e.g., a greater emphasis on primary mental health care. The need, desirability and obstacles to the development of a mental health system that embraces primary mental health care has been documented (Pillay and Subedar, 1992).

While this type of system may be desirable from the perspective of the general population (especially those who currently have limited or no access to mental health resources because of inability to pay or lack of resources) this alternative would be resisted by those with generous health insurance coverage and providers who are currently in the private sector as this system would mean reduced autonomy and possibly, reduced renumeration. Mental health workers currently in private practice may emigrate as a consequence. This may be considered a problem given the existing short supply of such workers (Freeman, 1992). However it is also possible that these are precisely the practitioners who may sabotage a new and possibly more equitable mental health system. This argument has been made by Navarro (personal communication) in relation to how the flight of physicians from Cuba in the 1960 s proved to be a benefit rather than a loss to the Cuban health system.

\section{(c) The National Health Insurance Service}

This type of health care system, which is typified by the Canadian, German and Dutch health care systems, has received a significant amount of coverage in the South African literature recently (de Beer and Broomberg, 1990). This has been largely a result of the influence of researchers at the Center for the Study of Health Policy at the University of the Witwatersrand.
There are many variations in the type of National Health Insurance Service. While the Canadians have a single state health insurance fund (into which a percentage of payroll is contributed by both employers and employees), the Germans have a system that can be divided into an insurance part and a social security part (Cooper and Bauer, 1987). In the German system, while the insurance component is financed by individual contributions and employers, the social security component is financed from general taxes.

The mental health providers within this system can all be in private practice as in Canada and Germany. The NHIS negotiates reimbursement rates with organizations that represent the providers. Renumeration to providers may be capped to prevent them from 'overservicing' i.e., providing more services than necessary so as to increase their incomes.

Consumers of mental health care under an insurance based system may not be covered for all types of mental health services, diagnoses or covered continuously. In Germany, for example those with chronic conditions are only eligible for insurance benefits for a limited period after which they may be covered by social security if eligible according to a means test (Cooper and Bauer, 1987).

In Canada the provision of mental health services falls under the jurisdiction of the provinces. Services are provided by either general hospitals or general practitioners. Access to mental health specialists is by referral from primary health care providers. The provinces have the option to levy user charges but none have exercised this option as yet (Health and Welfare Canada, 1990).

In terms of what mental health benefits are covered and mental health expenditure per capita, it is possible to mandate a single national package of mental health services that would be provided under a NHIS. This has not been achieved in Canada. In Canada where there is a significant degree of provincial autonomy, the provinces vary in mental health expenditure per capita and the type and extent of services that they provide. While the province of Newfoundland spends $\$ 69.16$ per capita, Manitoba spends \$188.27 (The Mental Health Services Work Group, 1991).

In the Netherlands, mental health care is fmanced on a per capita basis by the Exceptional Medical Expenses Act and provided by 60 Regional Institutes for 
Out-Patient Mental Health Care (RIAGGs), each of which serve a catchment area of between 150,000 and 300,000 people (Ministry of Welfare, Health and Cultural Affairs, 1989). The RIAGGs provide both preventive and curative (e.g., crisis intervention and short term psychotherapy) services. Except for psychotherapy, all other services are provided free of charge.

If there are many exclusions from those mental health services covered by the NHIS, then the cost to the individual will be higher than that to the state and employers. Depending on the type of NHIS introduced, it is possible that such a system may reduce the possibility of cost containment and comprehensive planning as the influence of market forces on production and distribution of mental health resources may increase. Most importantly, from the perspective of equity, the system may increase the possibility of the introduction of a widely disparate two-tiered mental health delivery system which then determines access to some resources by ability to pay rather than by need.

From the perspective of those controlling private mental health resources (both physical such as private hospitals and clinics and skills such as, those practitioners in private practice), a NHIS may be acceptable especially if their incomes increase or do not change and their autonomy is not threatened. Consumers, on the other hand, may not welcome a system that is not comprehensive, requires a considerable amount of out-of-pocket payments and in which access to some resources are determined by ability to pay rather than need.

\section{(d) Conclusions}

In determining which health care system South Africa should adopt it is crucial that the consequences for mental health care be considered. While it can be argued that there are similarities between mental and physical health as in the responsiveness of some forms of mental disorders to pharmacotherapy, there are also differences (e.g., the uncertain etiology, the difficulty in diagnosing and treating, and the level of chronicity of a large number of mental disorders).

Mental health workers and current consumers and their families possibly have the greatest stake in the determination of the type of mental health policy including its financing, production, distribution and delivery adopted by South Africa in the future.

While this paper has not taken a position, in terms of stating a preference, it has attempted to: (1) suggest some of the issues that need to be considered; and (2) illustrate how these issues may be affected by three types of health care systems. While it may be argued that one should suggest a desired option the author considers this premature given the need for broad participation in policy formulation and the need for a well informed electorate under a system of universal adult suffrage to determine national policy. The objective of this paper therefore is intended to assist in the informing process.

\section{REFERENCES}

COOPER, B. \& BAUER, M. (1987). Developments in Mental Health Care and Services in the Federal Republic of Germany. International Joumal of Mental Health, 16:78-93.

Critical Health (1991). number 35:43-49.

DAWES, A. (1986). The notion of relevant psychology with particular reference to Africanist pragmatic initiatives. Psychology in Society, 5:28-48.

DE BEER, C. AND BROOMBERG, J. (1990). Financing health care for all is national health insurance the first step? South African Medical Joumal, 78:144-148.

FREEMAN, M. (1990). Decentralised Responsibility - a way forward for 'homeland' mental health care. South African Medical Joumal, 77:478-80.

FREEMAN, M. (1992). Providing mental health care for all in South Africa - structure and strategy. The Center for Health Policy. Johannesburg.

HAYES, G. (1987). Challenges to psychotherapy in the context of social service work. Mental Health in Transition: OASSSA Second National Conference Proceedings.

HEALTH AND WELFARE CANADA (1990). Mental Health Services in Canada 1990.
JANSEN, M. A. (1986). Mental Health Policy:Observations from Europe. American Psychologist, 41:1273-1278.

KRIEGLER, S. M.; MOLLER, A. T.; \& SCHOEMAN, J. B. (1989). The PASA report on mental health in South Africa:Implications for future training of psychologists. Unpublished paper presented at the PASA national training symposium.

MINISTRY OF WELFARE, HEALTH AND CULTURAL AFFAIRS (1989). Fact Sheet on the Netherlands.

NAVARRO, V. (1992). Personal communication.

PILLAY, Y. G. (1992). Ethical issues in the transformation of health policy in South Africa. South African Medical Joumal, 82:32-34.

PILLAY, Y.G. AND SUBEDAR, H. (1992). Primary mental health care: indications and obstacles. Curationis, 15:5-7.

POVEDA, J. M., GARCIA, S., PALOMO, E. AND OCTAVIO, O. (1987). Mental Health Care in Spain, 1960-1985. International Joumal of Mental Health, 16:182-197.

ROEMER, M. I. \& ROEMER, J. E. (1982). The social consequences of free trade in health care:a public health response to orthodox economics. Intemational Joumal of Health Services, 12:111-129.

THE MENTAL HEALTH SERVICES WORK GROUP (1991). Towards Rebalancing Canada's Mental Health System. Canadian Mental Health Association.

VOGELMAN, L. (1989). Psychology, mental health care and the future: is appropriate transformation in post-apartheid South Africa possible? Social Science and Medicine, 31:501-505. 